\title{
New Kinetic Spectrophotometric Method for Determination of Fexofenadine Hydrochloride in Pharmaceutical Formulations
}

\author{
Safwan Ashour and Mouhammed Khateeb \\ Analytical Biochemistry Laboratory, Department of Chemistry, Faculty of Sciences, University of Aleppo, Aleppo, Syria \\ Correspondence should be addressed to Safwan Ashour; profashour@hotmail.com
}

Received 27 February 2014; Revised 16 April 2014; Accepted 17 April 2014; Published 29 June 2014

Academic Editor: Hicham Fenniri

Copyright ( 2014 S. Ashour and M. Khateeb. This is an open access article distributed under the Creative Commons Attribution License, which permits unrestricted use, distribution, and reproduction in any medium, provided the original work is properly cited.

\begin{abstract}
A simple and sensitive kinetic spectrophotometric method was developed for the determination of fexofenadine hydrochloride in bulk and pharmaceutical preparations. The method is based on a kinetic investigation of the oxidation reaction of fexofenadine using alkaline potassium permanganate as an oxidizing agent at room temperature. The reaction is followed spectrophotometrically by measuring the increase of absorbance owing to the formation of manganate ion at $610 \mathrm{~nm}$. The initial rate and fixed time (at $15 \mathrm{~min}$ ) methods are utilized for construction of calibration graphs. All the reaction conditions for the proposed method have been studied. The linearity range was found to be $2.5-50.0 \mu \mathrm{g} \mathrm{mL} \mathrm{L}^{-1}$ with detection limit of $0.055 \mu \mathrm{g} \mathrm{mL} \mathrm{m}^{-1}$ for both initial rate and fixed time methods. The proposed method was applied successfully for the determination of fexofenadine in pharmaceutical formulations; the percentage recoveries were $99.98-101.96 \%$. The results obtained were compared statistically with those obtained by the official method and showed no significant differences regarding accuracy and precision.
\end{abstract}

\section{Introduction}

Fexofenadine, $( \pm)$-4-[1-hydroxy-4-[4-(hydroxyl diphenylmethyl)-1-piperidinyl]butyl]-alpha, alpha-dimethyl benzene acetic acid, an active metabolite of terfenadine, is a selective histamine $\mathrm{H}_{1}$-receptor antagonist and is clinically effective in the treatment of seasonal allergic rhinitis and chronic idiopathic urticaria as a first-line therapeutic agent, such as loratadine and cetirizine [1]. Several methods for the determination of fexofenadine hydrochloride in pharmaceutical formulations and biological fluids have been reported including HPLC [2-5], spectrophotometry [5-9], extractive spectrophotometry and conductometry [10], spectrofluorometry [11], potentiometry [12], and capillary electrophoresis $[13,14]$. Fexofenadine hydrochloride has been determined in combination with other drugs using HPLC [15-19], HPTLC [20], and spectrophotometry [21-23] in combined dosage forms. Fexofenadine has been determined in human plasma by HPLC with UV detection [24], fluorescence detection [25], and tandem mass spectrometry detection [26-28].
Kinetic methods have certain advantages in pharmaceutical analysis regarding selectivity and elimination of additive interferences, which affect direct spectrophotometric methods. The literature is still poor in analytical assay methods based on kinetics for the determination of fexofenadine in dosage forms. Some specific advantages that the kinetic methods possess are as follows: simple and fast methods because some experimental steps such as filtration and extraction are avoided prior to absorbance measurements; high selectivity since they involve the measurement of the absorbance as a function of reaction time instead of measuring the concrete absorbance value; other active compounds present in the commercial dosage forms which may not interfere if they are resisting the chemical reaction conditions established for the proposed kinetic method, and colored and/or turbid sample background which may not possibly interfere with the determination process $[29,30]$.

In our study fexofenadine was found to react with permanganate in alkaline medium; the reaction yielded a bluish 
green manganate with a $\lambda_{\max }$ at $610 \mathrm{~nm}$. This color reaction was studied for the direct spectrophotometric determination of the drug. Optimum conditions were established and the method was validated for linearity, sensitivity, accuracy, and precision. The validated method when applied to the determination of FEX in formulations yielded results which were in agreement with the label claim.

\section{Experimental}

2.1. Apparatus. A Jasco V-530 UV-VIS spectrophotometer (Japan) with $1 \mathrm{~cm}$ quartz cells was used for all absorbance measurements under the following operating conditions: scan speed medium (400 nm/min), scan range $350-700 \mathrm{~nm}$, and slit width $2 \mathrm{~nm}$. Spectra were automatically obtained by Jasco system software. $\mathrm{pH}$ measurements were made with Consort C830 (Belgium) with combined glass pH electrode.

2.2. Reagents and Materials. All chemicals and reagents used throughout this work were of analytical reagent grade and supplied by Merck (Germany) and solutions were made with doubly distilled water. Fexofenadine hydrochloride (FEX) was obtained from Chem Pharma (India). The purity of FEX was found to be $99.86 \%$ according to BP [31]. Pharmaceutical preparations containing FEX were purchased from commercial sources in the local market.

Stock solutions, $1.0 \times 10^{-2} \mathrm{M}$ of potassium permanganate and $1.0 \mathrm{M}$ of sodium hydroxide, were prepared by dissolving the accurately weighed amounts of the pure solid in doubly distilled water. Absolute methanol was used to prepare the drug sample solution. Stock solution, $0.25 \mathrm{mg} \mathrm{mL}^{-1}$ of FEX, was prepared in doubly distilled water, stored in dark bottles, and kept in the refrigerator for no more than 10 days. Other concentrations of working solutions were then prepared by suitable dilution of the stock solution with water.

2.3. Procedure for Initial Rate Method. Aliquots of $2.5-50 \mu \mathrm{g} \mathrm{mL}^{-1}$ of FEX test solution $(0.10-2.00 \mathrm{~mL}$, $0.25 \mathrm{mg} \mathrm{mL}^{-1}$ ) were pipetted into a series of $10 \mathrm{~mL}$ volumetric flask. $1.0 \mathrm{~mL}$ of potassium permanganate solution $(0.01 \mathrm{M})$ was added followed by $1 \mathrm{~mL}$ of sodium hydroxide solution $(1.0 \mathrm{M})$ to each flask and then diluted to the volume with double distilled water at $25^{\circ} \mathrm{C}$. The content of mixture of each flask was mixed well and the increase in absorbance at $610 \mathrm{~nm}$ was recorded as a function of time over $0-20 \mathrm{~min}$ against reagent blank treated similarly. The initial rate of the reaction $(\nu)$ at different concentrations was obtained from the slope of the tangent to absorbance time curves. The calibration graphs were constructed by plotting the logarithm of the initial rate of the reaction $(\log v)$ versus $\operatorname{logarithm}$ of molar concentration of FEX $(\log C)$.

2.4. Procedure for Fixed Time Method. Aliquots of $2.5-50 \mu \mathrm{g} \mathrm{mL}^{-1}$ of FEX test solution $(0.10-2.00 \mathrm{~mL}$, $0.25 \mathrm{mg} \mathrm{mL}^{-1}$ ) were pipetted into a series of $10 \mathrm{~mL}$ volumetric flask. $1.0 \mathrm{~mL}$ of potassium permanganate solution $(0.01 \mathrm{M})$ was added followed by $1 \mathrm{~mL}$ of sodium hydroxide solution

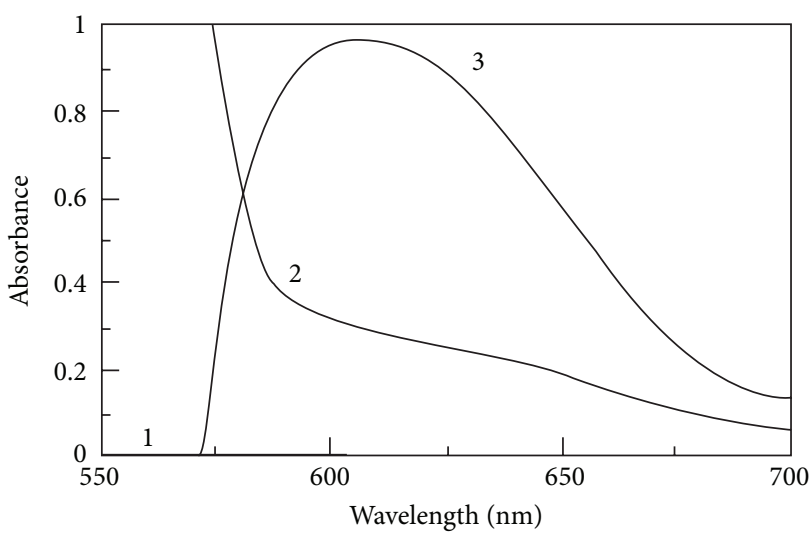

FIgURE 1: Absorption spectra of (1) $45 \mu \mathrm{g} \mathrm{mL}^{-1}$ FEX solution against water, (2) reagent blank solution against water, and (3) the reaction product of FEX $\left(45 \mu \mathrm{g} \mathrm{mL}^{-1}\right)$ with alkaline potassium permanganate against reagent blank.

$(1.0 \mathrm{M})$ to each flask and then diluted to the volume with double distilled water at $25^{\circ} \mathrm{C}$. The content of mixture of each flask was mixed well and the absorbance of each sample solution at preselected fixed time (15 min) was accurately measured and plotted against the final concentration of the drug.

2.5. Procedure for Pharmaceutical Formulations. Twenty tablets were weighted accurately and crushed to a fine powder. In the case of capsules, the contents of twenty capsules were completely evacuated from shells. An accurately weighed quantity of the powder equivalent to $25 \mathrm{mg}$ of the cited drug was dissolved in $50 \mathrm{~mL}$ of methanol and mixed for about $15 \mathrm{~min}$ and then filtered through Whatman filter paper number 40 . The methanol was evaporated to dryness. The remaining portion of solution was dissolved in a $100 \mathrm{~mL}$ volumetric flask to the volume with double distilled water to achieve a concentration of $0.25 \mathrm{mg} \mathrm{mL}^{-1}$. The general procedure was then followed in the concentration ranges mentioned above.

\section{Results and Discussion}

Potassium permanganate in alkaline medium oxidizes FEX and yields the bluish green color due to the production of manganate ion which is absorbed maximally at $610 \mathrm{~nm}$ as shown in Figure 1. The absorbance of the reaction product remains stable for at least $60 \mathrm{~min}$. The increase in the intensity of the color by time was used as a basis for a useful kinetic method for the determination of FEX in pharmaceutical formulation.

3.1. Optimization of Reaction Conditions. The spectrophotometric properties of the colored product as well as the different experimental parameters affecting the color development and its stability were studied and optimized by changing each variable in turn, while keeping all the others constant. The effect of potassium permanganate concentration on the reaction was studied over the range 


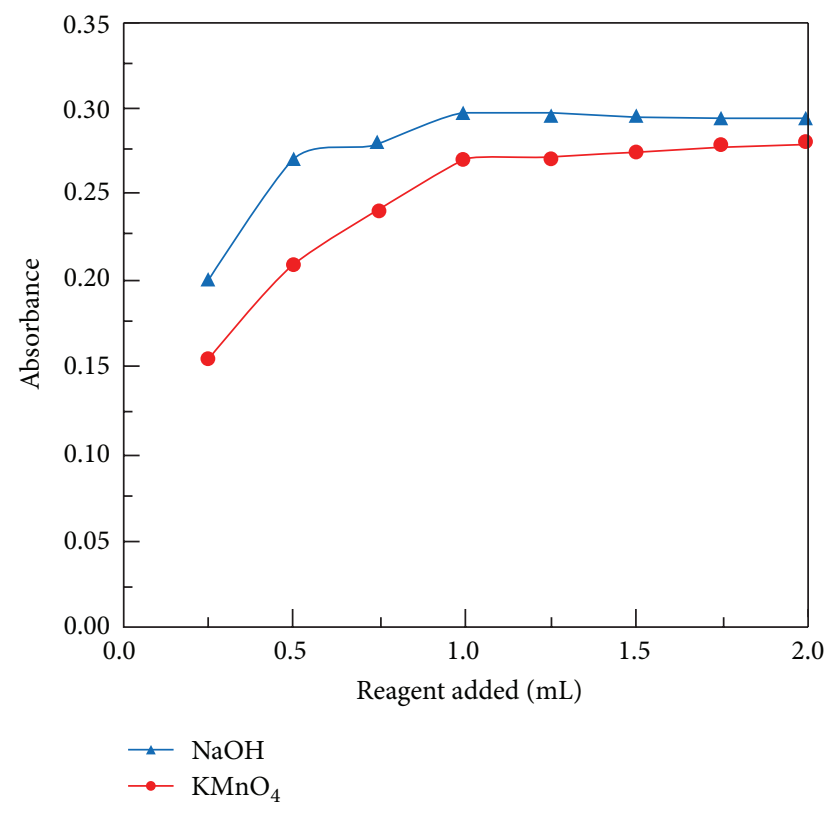

FIgURE 2: Effect of $0.01 \mathrm{M} \mathrm{KMnO}_{4}$ or $1.0 \mathrm{M} \mathrm{NaOH}$ volume on the absorbance at $610 \mathrm{~nm}$ of reaction product of $15 \mu \mathrm{g} \mathrm{mL}^{-1}$ FEX measured at room temperature in final volume of $10 \mathrm{~mL}$.

$2.5 \times 10^{-4}-2.0 \times 10^{-3} \mathrm{M}$, in the final concentration. The maximum absorbance was obtained at concentration of $1.0 \times 10^{-3} \mathrm{M}$ (when $1.0 \mathrm{~mL}$ of $0.01 \mathrm{M} \mathrm{KMnO}_{4}$ was added). Complete reaction between FEX and potassium permanganate takes place only in alkaline medium. The influence of the medium alkalinity was investigated between $2.5 \times 10^{-2}$ and $0.2 \mathrm{M}$ sodium hydroxide. $0.1 \mathrm{M}$ sodium hydroxide in the final concentration $(1 \mathrm{~mL}$ of $1.0 \mathrm{M}$ sodium hydroxide) was chosen for all subsequent experiments (Figure 2).

The effect of temperature on the reaction of FEX with $\mathrm{KMnO}_{4}$ in alkaline medium was studied at different values $\left(20-55^{\circ} \mathrm{C}\right)$ by continuous monitoring of the absorbance at $610 \mathrm{~nm}$. It was found that the reaction with $\mathrm{KMnO}_{4}$ was not affected by increasing the temperature, and the reaction at laboratory ambient temperature $\left(25 \pm 5^{\circ} \mathrm{C}\right)$ went to completion within $15 \mathrm{~min}$. The results revealed that increasing the temperature $\left(>55^{\circ} \mathrm{C}\right)$ had negative effect on the absorption values of the reaction solution.

3.2. Quantitation Methods. Because the intensity of the color increased at $610 \mathrm{~nm}$ with time (Figure 3), this was used as the basis for a useful kinetic method for the determination of FEX. The initial rate, rate constant, fixed absorbance, and fixed time methods [32, 33] were tested and the most suitable analytical methods were chosen regarding the applicability, sensitivity, and the values of the intercept and correlation coefficient $\left(R^{2}\right)$.



FIgURE 3: Absorbance-time curve for reaction of FEX with $\mathrm{KMnO}_{4}$ in $\mathrm{NaOH}$ medium; $\mathrm{C}_{\mathrm{FEX}}: 2.5-50 \mu \mathrm{g} \mathrm{mL}^{-1}$.

3.2.1. Initial Rate Method. The initial rate of reaction would follow a pseudo order rate constant and obeyed the following rate equation:

$$
v=\frac{\Delta A}{\Delta t}=k^{\prime} C^{n},
$$

where $v$ is the reaction rate, $A$ is the absorbance, $t$ is the measuring time, $k^{\prime}$ is the pseudo order rate constant, $C$ is the concentration of the drug $\mathrm{mol} / \mathrm{L}$, and $n$ is the order of the reaction. A calibration curve was constructed by plotting the logarithm of the initial rate of reaction $(\log v)$ versus $\log$ arithm of drug concentration $(\log C)$ which showed a linear relationship over the concentration range of 2.5-50.0 $\mu \mathrm{g} \mathrm{mL}^{-1}$ (Figure 4). The logarithmic form of the above equation is written as follows:

$$
\begin{array}{r}
\log \nu=\log \frac{\Delta A}{\Delta t}=\log k^{\prime}+n \log C, \\
\log v=\log \frac{\Delta A}{\Delta t}=0.5777+0.9269 \log [\mathrm{FEX}] \\
\left(R^{2}=0.9996\right) .
\end{array}
$$

Thus, $k^{\prime}=3.78 \mathrm{~S}^{-1}$, and the reaction is the first order $(n=$ $0.9269 \approx 1$ ) with respect to FEX concentration.

3.2.2. Rate Constant Method. The logarithm of the absorbance of reaction versus time for each concentration of FEX studied over the concentration range of $2.5-50.0 \mu \mathrm{g} \mathrm{mL}^{-1}$ (Figure 3) was calculated. Graphs of log absorbance versus time for FEX concentration in the range of $30.0-45.0 \mu \mathrm{g} \mathrm{mL}^{-1}\left(5.57 \times 10^{-5}-8.36 \times 10^{-5} \mathrm{M}\right)$ were plotted and all appeared to be rectilinear. Pseudo order rate constants $\left(k^{\prime}\right)$ corresponding to different FEX concentrations 
TABLE 1: Regression equations for FEX at fixed time and $25^{\circ} \mathrm{C}$.

\begin{tabular}{|c|c|c|c|}
\hline Time (min) & Regression equation & Correlation coefficient & Linear range $\left(\mu \mathrm{g} \mathrm{mL}^{-1}\right)$ \\
\hline 0 & $A=0.0058 C+0.0111$ & 0.9971 & $2.5-50.0$ \\
\hline 5 & $A=0.0149 C+0.0028$ & 0.9981 & $2.5-50.0$ \\
\hline 10 & $A=0.0190 C+0.0094$ & 0.9993 & $2.5-50.0$ \\
\hline 15 & $A=0.0209 C+0.0240$ & 0.9997 & $2.5-50.0$ \\
\hline 20 & $A=0.0221 C+0.0350$ & 0.9991 & $2.5-50.0$ \\
\hline 25 & $A=0.0229 C+0.0495$ & 0.9968 & $2.5-50.0$ \\
\hline 30 & $A=0.0233 C+0.0645$ & 0.9943 & $2.5-50.0$ \\
\hline
\end{tabular}

$A$ : absorbance; $C$ : concentration.

TABLE 2: Analytical characteristics of the fixed time (15 min) method.

\begin{tabular}{lc}
\hline Parameters & FEX \\
\hline$\lambda_{\max }(\mathrm{nm})$ & 610 \\
Beer's law range $\left(\mu \mathrm{g} \mathrm{mL}^{-1}\right)$ & $2.5-50.0$ \\
Ringbom optimum concentration range $\left(\mu \mathrm{g} \mathrm{mL}^{-1}\right)$ & $10.0-40.0$ \\
Detection limit $\left(\mu \mathrm{g} \mathrm{m}^{-1}\right)$ & 0.055 \\
Quantification limit $\left(\mu \mathrm{g} \mathrm{mL}^{-1}\right)$ & 0.183 \\
Molar absorptivity $\left(\mathrm{L} \mathrm{mol}^{-1} \mathrm{~cm}^{-1}\right)$ & $1.22 \times 10^{4}$ \\
Stoichiometric relationship, FEX $: \mathrm{KMnO}_{4}$ & $1: 1$ \\
Sandell's sensitivity $\left(\mu \mathrm{g} \mathrm{cm}^{-2}\right.$ per 0.001 absorbance unit) & 0.088 \\
Regression equation & \\
Correlation coefficient, $R^{2}$ & $A=0.0209 C+0.024$ \\
\hline
\end{tabular}

${ }^{\mathrm{a}} A=m C+b$, where $A$ is the absorbance and $C$ is the concentration in $\mu \mathrm{g} \mathrm{mL}^{-1}$.

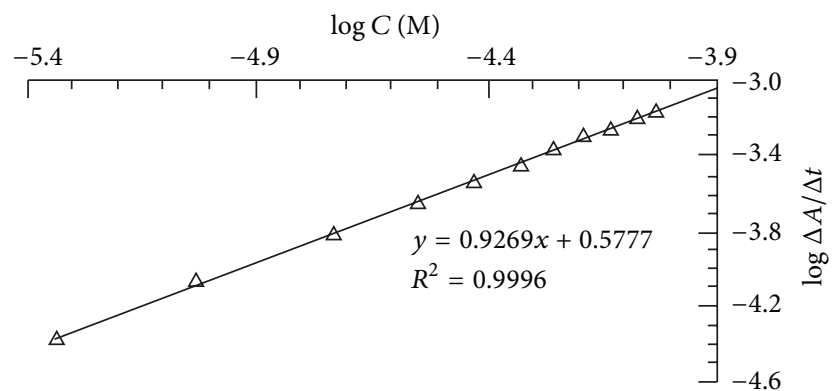

FIgURE 4: Calibration plot of logarithm rate of the reaction against logarithm molar concentration of FEX for initial rate method.

were calculated from the slopes multiplied by -2.303 and are presented in Figure 5. Regression of $C$ versus $k^{\prime}$ gave the following equation:

$$
k^{\prime}=2.9451 C-0.00085 \quad\left(R^{2}=0.9538\right) .
$$

3.2.3. Fixed Absorbance Method. Reaction rate data were recorded for different FEX concentrations in the range $30.0-50.0 \mu \mathrm{g} \mathrm{mL}^{-1}$. A preselected value of the absorbance 0.75 was fixed and the time was measured in seconds. The reciprocal of time $(1 / t)$ versus the initial concentration of

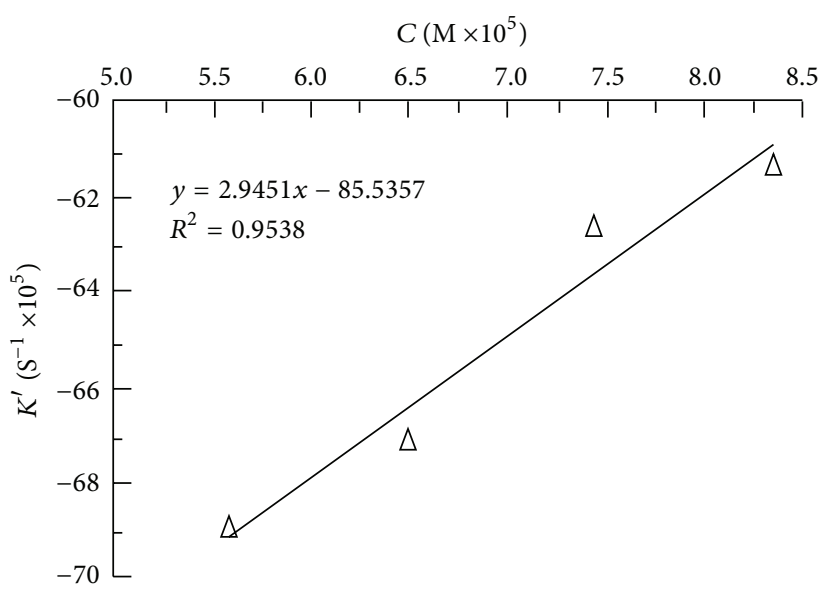

FIgURE 5: Calibration plot of FEX for rate constant method.

FEX was plotted (Figure 6) and the following equation of calibration graph was obtained:

$$
\frac{1}{t}=-0.00334+70.847 C \quad\left(R^{2}=0.9884\right) .
$$

The range of FEX concentrations giving the most satisfactory results was limited $30.0-50.0 \mu \mathrm{g} \mathrm{mL}^{-1}\left(5.57 \times 10^{-5}-9.29 \times\right.$ $\left.10^{-5} \mathrm{M}\right)$. 
TABLE 3: Accuracy and precision for the determination of FEX in bulk powder by the proposed initial rate and fixed time methods.

\begin{tabular}{|c|c|c|c|c|c|c|}
\hline \multirow{2}{*}{ Method } & \multicolumn{3}{|c|}{$\mathrm{FEX}, \mu \mathrm{g} \mathrm{mL}^{-1}$} & \multirow{2}{*}{$\mathrm{RSD} \%$} & \multirow{2}{*}{$\begin{array}{l}\text { Confidence limit } \\
(P=0.05 ; n=6)\end{array}$} & \multirow{2}{*}{ Recovery\% } \\
\hline & Taken & Found $^{\mathrm{a}}$ & $\mathrm{SD}$ & & & \\
\hline \multirow{4}{*}{ Initial rate } & 5.00 & 5.01 & 0.12 & 2.39 & $5.01 \pm 0.13$ & 100.20 \\
\hline & 20.00 & 20.20 & 0.20 & 0.99 & $20.20 \pm 0.22$ & 101.00 \\
\hline & 35.00 & 34.90 & 0.28 & 0.80 & $34.90 \pm 0.31$ & 99.71 \\
\hline & 50.00 & 50.13 & 0.14 & 0.28 & $50.13 \pm 0.15$ & 100.26 \\
\hline \multirow{4}{*}{ Fixed time } & 5.00 & 5.04 & 0.13 & 2.58 & $5.04 \pm 0.15$ & 100.80 \\
\hline & 20.00 & 20.14 & 0.30 & 1.49 & $20.14 \pm 0.34$ & 100.70 \\
\hline & 35.00 & 35.00 & 0.32 & 0.91 & $35.00 \pm 0.36$ & 100.00 \\
\hline & 50.00 & 50.31 & 0.36 & 0.71 & $50.31 \pm 0.40$ & 100.62 \\
\hline
\end{tabular}

${ }^{a}$ Average of six determinations.

TABLE 4: Determination of FEX in different pharmaceutical formulations by the proposed and official methods.

\begin{tabular}{|c|c|c|c|c|}
\hline \multirow{3}{*}{ Formulation } & \multirow{3}{*}{ Label claim } & \multicolumn{3}{|c|}{$\%$ Found $^{\mathrm{a}} \pm \mathrm{SD}$} \\
\hline & & \multicolumn{2}{|c|}{ Proposed methods } & \multirow[t]{2}{*}{ Official method [31 } \\
\hline & & Initial rate & Fixed time & \\
\hline \multirow{9}{*}{ Allergy stop ${ }^{b}$} & \multirow{3}{*}{60 mg/Cap } & $100.75 \pm 0.19$ & $101.04 \pm 0.21$ & $100.79 \pm 0.13$ \\
\hline & & $t=1.99$ & $t=2.17$ & $t=1.32$ \\
\hline & & $F=2.14$ & $F=2.61$ & \\
\hline & \multirow{3}{*}{$120 \mathrm{mg} / \mathrm{Tab}$} & $101.06 \pm 0.20$ & $100.12 \pm 0.18$ & $101.05 \pm 0.15$ \\
\hline & & $t=2.05$ & $t=1.75$ & $t=1.28$ \\
\hline & & $F=1.78$ & $F=1.44$ & \\
\hline & \multirow{3}{*}{180 mg/Tab } & $99.98 \pm 0.18$ & $100.60 \pm 0.20$ & $99.78 \pm 0.14$ \\
\hline & & $t=1.68$ & $t=1.36$ & $t=1.79$ \\
\hline & & $F=1.65$ & $F=2.04$ & \\
\hline \multirow{3}{*}{ Fexofenadine $^{c}$} & \multirow{3}{*}{60 mg/Cap } & $100.27 \pm 0.15$ & $101.00 \pm 0.13$ & $100.84 \pm 0.11$ \\
\hline & & $t=1.99$ & $t=1.00$ & $t=1.88$ \\
\hline & & $F=1.86$ & $F=1.41$ & \\
\hline \multirow{6}{*}{ Fenadin $^{\mathrm{d}}$} & \multirow{3}{*}{120 mg/Tab } & $101.96 \pm 0.13$ & $100.26 \pm 0.14$ & $99.69 \pm 0.12$ \\
\hline & & $t=1.67$ & $t=2.06$ & $t=1.24$ \\
\hline & & $F=1.17$ & $F=1.52$ & \\
\hline & \multirow{3}{*}{$180 \mathrm{mg} / \mathrm{Tab}$} & $100.95 \pm 0.20$ & $101.08 \pm 0.23$ & $100.52 \pm 0.18$ \\
\hline & & $t=1.70$ & $t=1.12$ & $t=1.81$ \\
\hline & & $F=1.23$ & $F=1.63$ & \\
\hline
\end{tabular}

${ }^{\mathrm{a}}$ Five independent analyses. At $95 \%$ confidence level $t$-value is 2.776 and $F$-value is 6.26 .

${ }^{\mathrm{b}}$ Supplied by Pharmasyr, Syria; ${ }^{\mathrm{c}}$ supplied by Ibn-Alhaytham, Syria; ${ }^{\mathrm{d}}$ supplied by BPI, Syria.

3.2.4. Fixed Time Method. At preselected fixed time, the absorbance of bluish green colored solution containing varying amounts of FEX was measured at $25^{\circ} \mathrm{C}$ and $610 \mathrm{~nm}$. Calibration graphs were constructed by plotting the absorbance against the initial concentration of FEX at fixed time 0-30 min. The regression equations, correlation coefficients, and linear ranges are given in Table 1.

It is clear that the slope increases with time and the most acceptable value of $R^{2}$ was obtained for a fixed time of $15 \mathrm{~min}$. Therefore, the fixed time of $15 \mathrm{~min}$ was utilized for the assay of FEX concentration. As a result, the most acceptable values of the correlation coefficient and linear range were obtained for the initial rate $(20 \mathrm{~min})$ and fixed time $(15 \mathrm{~min})$ methods.
Thus, they were used for the determination of FEX in pure form and pharmaceutical formulations.

\subsection{Analytical Method Validation}

3.3.1. Calibration Graph. After optimizing the reaction conditions, the fixed time was applied to the determination of FEX in pure form over the concentration range 2.5-50.0 $\mathrm{g} \mathrm{mL}^{-1}$. A linear relationship was found between the absorbance at $\lambda_{\max }$ and the concentration of the FEX in the mentioned range. Analysis of the data gave the regression equation shown in Table 2. Regression analysis of Beer's law 


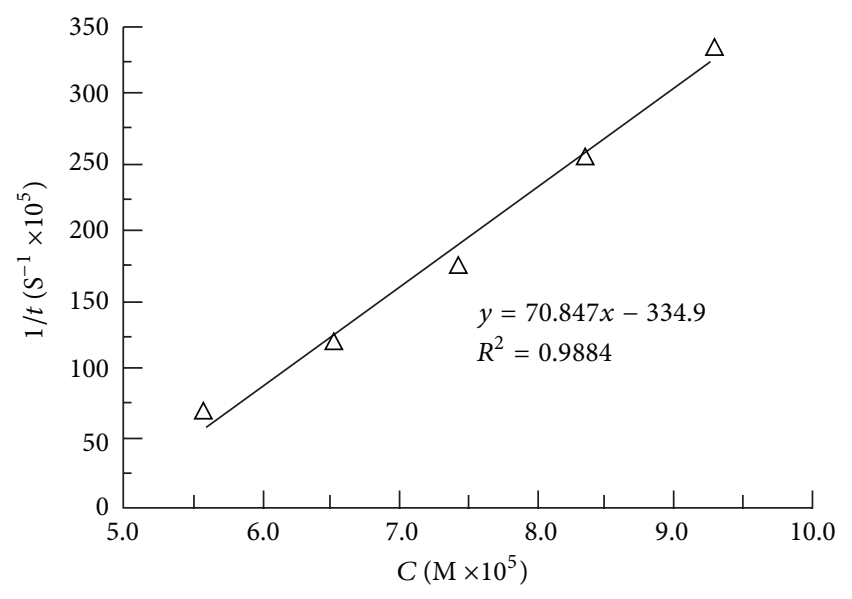

FIGURE 6: Calibration plot of FEX for fixed absorbance method.

plots reveals a good correlation. The graph shows negligible intercept and is described by the regression equation, $A=$ $m C+b$ (where $A$ is the absorbance of $1 \mathrm{~cm}$ layer, $m$ is the slope, $b$ is the intercept, and $C$ is the concentration of the measured solution in $\mu \mathrm{g} \mathrm{mL}^{-1}$ ) obtained by the least-squares method [34].

3.3.2. $L O D$ and $L O Q$. The minimum level at which the investigated compound can be reliably detected (limit of detection, LOD) and quantified (limit of quantitation, LOQ) was determined experimentally for fixed time (15 min) method. The LOD was expressed as the concentration of drug that generated a response to three times of the signal to-noise $(\mathrm{S} / \mathrm{N})$ ratio, and the LOQ was 10 times of the $\mathrm{S} / \mathrm{N}$ ratio. The LOD of FEX attained as defined by IUPAC [35], $\operatorname{LOD}_{(k=3)}=k \times S_{a} / b$ (where $b$ is the slope of the calibration curve and $S_{a}$ is the standard deviation of the intercept), was found to be $0.055 \mu \mathrm{g} \mathrm{mL}^{-1}$. The LOQ was also attained according to the IUPAC definition, $\mathrm{LOQ}_{(k=10)}=$ $k \times S_{a} / b$, and was found to be $0.183 \mu \mathrm{g} \mathrm{mL}^{-1}$. Sandell's index represents the number of micrograms or nanograms of the determinant per milliliter of a solution having an absorbance of 0.002 for the cell path length of $1 \mathrm{~cm}$ and is a suitable parameter for expressing and comparing the sensitivity of developed spectrophotometric method. Sandell's sensitivity coefficient of FEX was found to be $0.088 \mu \mathrm{g} \mathrm{cm}^{-2}$ per 0.001 absorbance unit (Table 2). The high molar absorptivity of the colored product indicates the high sensitivity of the method. For more accurate analysis, Ringbom optimum concentration range was calculated [36]. Table 2 shows the values of molar absorptivity, Sandell's sensitivity, and some analytical characteristics for fixed time $(15 \mathrm{~min})$ method.

3.3.3. Accuracy and Precision. The accuracy and precision of the proposed method were carried out by six determinations at four different concentrations. Percentage relative standard deviation (RSD\%) as precision and percentage recovery as accuracy of the suggested methods were calculated and shown in Table 3. The values of relative standard deviations for different concentrations of FEX are determined from the calibration curves. These results of accuracy and precision show that the proposed methods have good repeatability and reproducibility. The proposed methods were found to be selective for the estimation of FEX in the presence of various tablet excipients. For this purpose, a powder blend using typical tablet excipients was prepared along with the drug and then analyzed. The recoveries were not affected by the excipients and the excipients blend did not show any absorption in the range of analysis.

3.4. Stoichiometry of the Reaction. The stoichiometry of the reaction was studied adopting the limiting logarithmic method [37]. The ratio of the reaction between FEX and $\mathrm{KMnO}_{4}$ in alkaline medium was calculated by dividing the slope of $\mathrm{KMnO}_{4}$ curve over the slope of the drug curve (Figures 7(a) and 7(b)). It was found that the ratio was 1:1 $\left(\mathrm{KMnO}_{4}\right.$ to FEX). The proposal pathway of the reaction is given as Scheme 1 where potassium permanganate in alkaline medium oxidizes FEX from enolic to ketonic form and yields the bluish green color due to the production of manganate ion.

3.5. Application to the Pharmaceutical Dosage Forms. The proposed techniques were applied to the tablets and capsules. The ingredients in the tablets and capsules did not interfere in the experiments. The applicability of the proposed methods for the assay of fexofenadine hydrochloride in formulations was examined by analyzing various formulations and the results tabulated in Table 4 were compared to the official HPLC method for fexofenadine hydrochloride [31] by means of $t$ - and $F$-values at 95\% confidence level. In all cases, the average results obtained by proposed methods and official method were statistically identical, as the difference between the average values had no significance at $95 \%$ confidence level. The low values of RSD show the results are reproducible. The proposed methods are simple, sensitive, and reproducible and can be used for routine analysis of fexofenadine hydrochloride in pure form and in formulations. The commonly used additives such as starch, lactose, glucose, and magnesium stearate do not interfere with the assay procedures.

\section{Conclusion}

The developed kinetic spectrophotometric method for the determination of fexofenadine hydrochloride in bulk and pharmaceutical formulations was sensitive, accurate, and precise. The limits of detection and quantitation were 0.055 and $0.183 \mu \mathrm{g} \mathrm{mL}^{-1}$, respectively. Potassium permanganate was used as an oxidizing agent in alkaline medium. The sample recoveries from all formulations were in good agreement with their respective label claims, which suggested noninterference of formulations excipients in the estimation. The developed method has more speed and higher sensitivity as compared to reported spectrophotometric methods and 


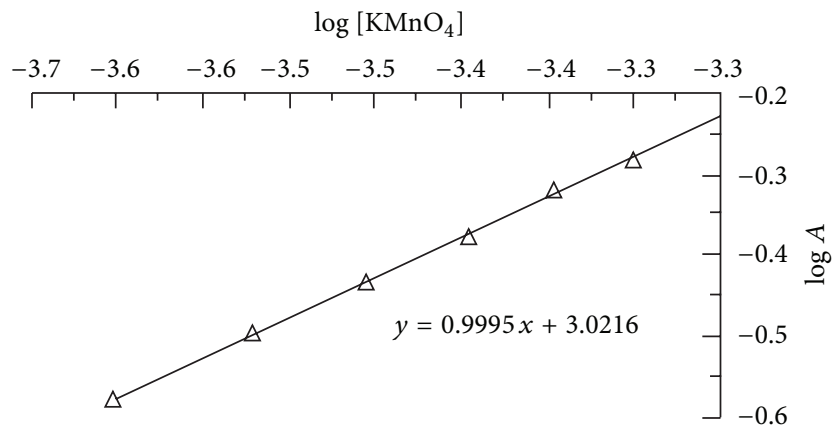

(a)

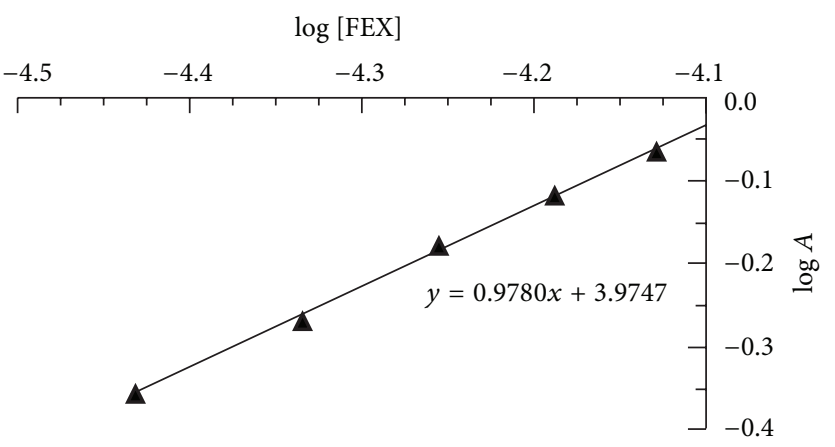

(b)

FIGURE 7: Stoichiometry of the reaction between FEX and alkaline potassium permanganate adopting limiting logarithmic method. (a) $C_{\mathrm{FEX}}=$ $2 \times 10^{-4} \mathrm{M}, C_{\mathrm{KMnO}_{4}}=2.5 \times 10^{-4}-5.0 \times 10^{-4} \mathrm{M}$ and (b) $C_{\mathrm{KMnO}_{4}}=1 \times 10^{-3} \mathrm{M}, C_{\mathrm{FEX}}=0.46 \times 10^{-5}-9.29 \times 10^{-5} \mathrm{M}$.<smiles></smiles>

SCHEME 1

has a wider range of linearity. Moreover, all the analytical reagents are inexpensive, have good shelf life, and are available in any analytical laboratory along with the lower reagents consumption leading to an environmentally friendly spectrophotometric procedure, which makes it especially suitable for routine quality control analysis work.

\section{Conflict of Interests}

There is no kind of financial gain between the authors and the mentioned corporations and identities inside the paper.

\section{References}

[1] C. S. Sean, Martindale, The Complete Drug Reference, Royal Pharmaceutical Society, Pharmaceutical Press, London, UK, 36th edition, 2009.

[2] A. R. Breier, S. C. Paim, J. Menegola, M. Steppe, and E. E. Schapoval, "Development and validation of a liquid chromatographic method for fexofenadine hydrochloride in capsules," Journal of AOAC International, vol. 87, no. 5, pp. 1093-1097, 2004.

[3] H. M. Maher, M. A. Sultan, and I. V. Olah, "Development of validated stability-indicating chromatographic method for the determination of fexofenadine hydrochloride and its related impurities in pharmaceutical tablets," Chemistry Central Journal, vol. 5, article 76, 2011.

[4] M. S. Arayne, N. Sultana, H. Shehnaz, and A. Haider, "RP-HPLC method for the quantitative determination of fexofenadine hydrochloride in coated tablets and human serum," Medicinal Chemistry Research, vol. 20, no. 1, pp. 55-61, 2011.
[5] I. Kozan, I. M. Palabiyik, E. Karacan, and F. Onur, "Spectrophotometric and high performance liquid chromatographic determination of fexofenadine hydrochloride in pharmaceutical formulations," Turkish Journal of Pharmaceutical Sciences, vol. 5, no. 3, pp. 175-189, 2008.

[6] A. A. Gazy, H. Mahgoub, F. A. El-Yazbi, M. A. El-Sayed, and R. M. Youssef, "Determination of some histamine H1-receptor antagonists in dosage forms," Journal of Pharmaceutical and Biomedical Analysis, vol. 30, no. 3, pp. 859-867, 2002.

[7] K. Suresh Kumar, V. Ravichandran, M. K. Mohan Maruga Raja, R. Thyagu, and A. Dharamsi, "Spectrophotometric determination of Fexofenadine hydrochloride," Indian Journal of Pharmaceutical Sciences, vol. 68, no. 6, pp. 841-842, 2006.

[8] S. J. Rajput and P. R. Parekh, "Spectrophotometric determination of fexofenadine hydrochloride in bulk drug and in its dosage form," Eastern Pharmacist, vol. 44, no. 527, pp. 101-103, 2001.

[9] P. V. Polawar, U. D. Shivhare, K. P. Bhusari, and V. B. Mathur, "Development and validation of spectrophotometric method of analysis for fexofenadine," Research Journal of Pharmacy and Technology, vol. 1, no. 4, pp. 539-541, 2008.

[10] S. Ashour, M. Khateeb, and R. Mahrouseh, "Extractive spectrophotometric and conductometric methods for determination of fexofenadine hydrochloride in pharmaceutical dosage forms," Pharmaceutica Analytica Acta, vol. S2, pp. 1-6, 2013.

[11] Z. A. Alothman, N. Bukhari, S. Haider, S. M. Wabaidur, and A. A. Alwarthan, "Spectrofluorimetric determination of fexofenadine hydrochloride in pharmaceutical preparation using silver nanoparticles," Arabian Journal of Chemistry, vol. 3, no. 4, pp. 251-255, 2010.

[12] M. N. Abbas, A. A. Fattah, and E. Zahran, "A novel membrane sensor for histamine H1-receptor antagonist fexofenadine," 
Analytical Sciences, vol. 20, no. 8, pp. 1137-1142, 2004.

[13] P. Mikuš, I. Valášková, and E. Havránek, "Determination of fexofenadine in tablets by capillary electrophoresis in free solution and in solution with cyclodextrins as analyte carriers," Drug Development and Industrial Pharmacy, vol. 31, no. 8, pp. 795-801, 2005.

[14] A. R. Breier, S. S. Garcia, A. Jablonski, M. Steppe, and E. E. S. Schapoval, "Capillary electrophoresis method for fexofenadine hydrochloride in capsules," Journal of AOAC International, vol. 88, no. 4, pp. 1059-1063, 2005.

[15] S. S. Zarapkar, N. P. Bhandari, and U. P. Halkar, "Simultaneous determination of Fexofenadine Hydrochloride and Pseudoephedrine Sulfate in pharmaceutical dosage by reverse phase high performance liquid chromatography," Indian Drugs, vol. 37, no. 9, pp. 421-425, 2000.

[16] T. Radhakrishna and G. O. Reddy, "Simultaneous determination of fexofenadine and its related compounds by HPLC," Journal of Pharmaceutical and Biomedical Analysis, vol. 29, no. 4, pp. 681-690, 2002.

[17] H. Vekaria, V. Limbasiya, and P. Patel, "Development and validation of RP-HPLC method for simultaneous estimation of montelukast sodium and fexofenadine hydrochloride in combined dosage form," Journal of Pharmacy Research, vol. 6, no. 1, pp. 134-139, 2013.

[18] S. Karakuş, İ. Küçükgüzel, and Ş. Güniz Küçükgüzel, "Development and validation of a rapid RP-HPLC method for the determination of cetirizine or fexofenadine with pseudoephedrine in binary pharmaceutical dosage forms," Journal of Pharmaceutical and Biomedical Analysis, vol. 46, no. 2, pp. 295-302, 2008.

[19] M. S. Arayne, N. Sultana, A. Z. Mirza, and F. A. Siddiqui, "Simultaneous determination of gliquidone, fexofenadine, buclizine, and levocetirizine in dosage formulation and human serum by RP-HPLC, Journal of Chromatographic Science, vol. 48, no. 5, pp. 382-385, 2010.

[20] S. S. Tandulwadkar, S. J. More, A. S. Rathore, A. R. Nikam, L. Sathiyanarayanan, and R. Kakasaheb, "Method development and validation for the simultaneous determination of fexofenadine hydrochloride and montelukast sodium in drug formulation using normal phase high-performance thin-layer chromatography," ISRN Analytical Chemistry, vol. 2012, Article ID 924185, 7 pages, 2012.

[21] H. Mahgoub, A. A. Gazy, F. A. El-Yazbi, M. A. El-Sayed, and R. M. Youssef, "Spectrophotometric determination of binary mixtures of pseudoephedrine with some histamine H1-receptor antagonists using derivative ratio spectrum method," Journal of Pharmaceutical and Biomedical Analysis, vol. 31, no. 4, pp. 801809, 2003.

[22] R. M. Maggio, P. M. Castellano, S. E. Vignaduzzo, and T. S. Kaufman, "Alternative and improved method for the simultaneous determination of fexofenadine and pseudoephedrine in their combined tablet formulation," Journal of Pharmaceutical and Biomedical Analysis, vol. 45, no. 5, pp. 804-810, 2007.

[23] H. J. Vekaria, K. S. Muralikrishna, and G. F. Patel, “Development and validation of spectrophotometric method for estimation of fexofenadine hydrochloride and montelukast sodium in combined dosage form," Pharm Analysis \& Quality Assurance, vol. 4, pp. 197-199, 2011.

[24] M. Miura, T. Uno, T. Tateishi, and T. Suzuki, "Determination of fexofenadine enantiomers in human plasma with highperformance liquid chromatography," Journal of Pharmaceutical and Biomedical Analysis, vol. 43, no. 2, pp. 741-745, 2007.
[25] T. Uno, N. Yasui-Furukori, T. Takahata, K. Sugawara, and T. Tateishi, "Liquid chromatographic determination of fexofenadine in human plasma with fluorescence detection," Journal of Pharmaceutical and Biomedical Analysis, vol. 35, no. 4, pp. 937942, 2004.

[26] E. A. Ö. Işleyen, T. Özden, S. Özilhan, and S. Toptan, “Quantitative determination of fexofenadine in human plasma by HPLCMS," Chromatographia, vol. 66, no. 1, pp. 109-113, 2007.

[27] N. Yamane, Z. Tozuka, Y. Sugiyama, T. Tanimoto, A. Yamazaki, and Y. Kumagai, "Microdose clinical trial: quantitative determination of fexofenadine in human plasma using liquid chromatography/electrospray ionization tandem mass spectrometry," Journal of Chromatography B: Analytical Technologies in the Biomedical and Life Sciences, vol. 858, no. 1-2, pp. 118-128, 2007.

[28] R. V. Nirogi, V. N. Kandikere, M. Shukla, K. Mudigonda, S. Maurya, and P. Komarnei, "Quantification of fexofenadine in human plasma by liquid chromatography couple to electrospray tandem mass spectrometry using mosapride as internal standard," Biomedical Chromatography, vol. 21, no. 2, pp. 209-216, 2007.

[29] D. Pérez-Bendito, A. Gómez-Hens, and M. Silva, "Advances in drug analysis by kinetic methods," Journal of Pharmaceutical and Biomedical Analysis, vol. 14, no. 8-10, pp. 917-930, 1996.

[30] S. Ashour, "New kinetic spectrophotometric method for determination of atorvastatin in pure and pharmaceutical dosage forms," Pharmaceutica Analytica Acta, vol. 4, no. 5, pp. 1-6, 2013.

[31] British Pharmacopœia, Her Majesty Stationery Officer, London, UK, 2013.

[32] M. Kopanica, V. Satra, K. Echschlager, I. Rorsak, Z. Koduys, and K. Sandr, Eds., Kinetic Methods in Chemical Analysis, Elsevier, Amsterdam, The Netherlands, 1983.

[33] D. Persez-Bendit and M. Silva, Kinetic Methods in Analytical Chemistry, chapter 11, John Wiley \& Sons, New York, NY, USA, 1988.

[34] J. N. Miller and J. C. Miller, Statistics and Chemometrics for Analytical Chemistry, Prentice Hall, London, UK, 5th edition, 2005.

[35] G. L. Long and J. D. Winefordner, "Limit of detection: a closer look at the IUPAC definition," Analytical Chemistry, vol. 55, no. 7, pp. 712-724, 1983.

[36] A. Ringbom, "Über die Genauigkeit der colorimetrischen Analysenmethoden I.," Zeitschrift für Analytische Chemie, vol. 115, no. 9-10, pp. 332-343, 1939.

[37] J. Rose, Advanced Physico-Chemical Experiments, Pittman, London, UK, 1964. 

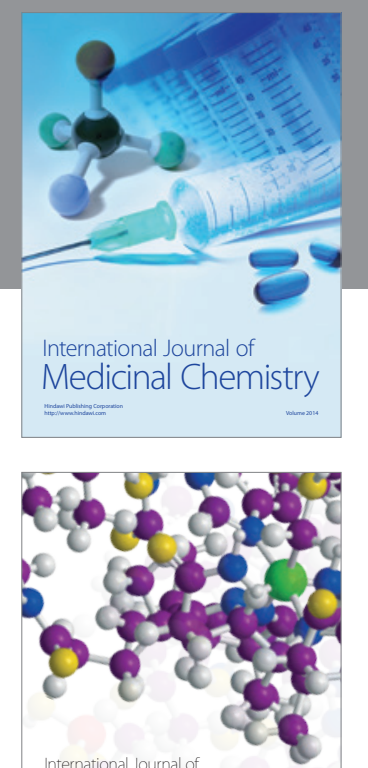

\section{Carbohydrate} Chemistry



The Scientific World Journal
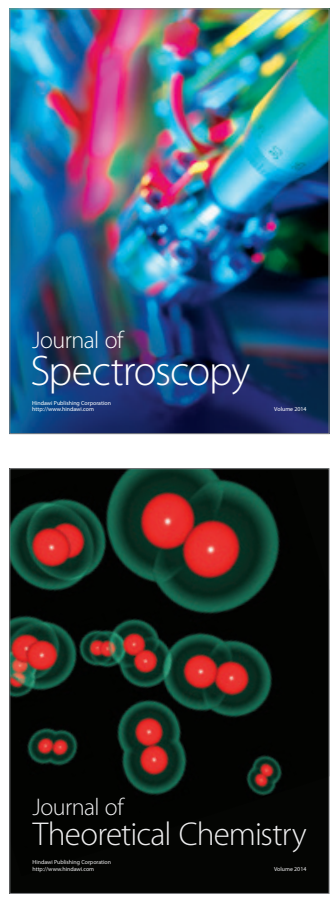
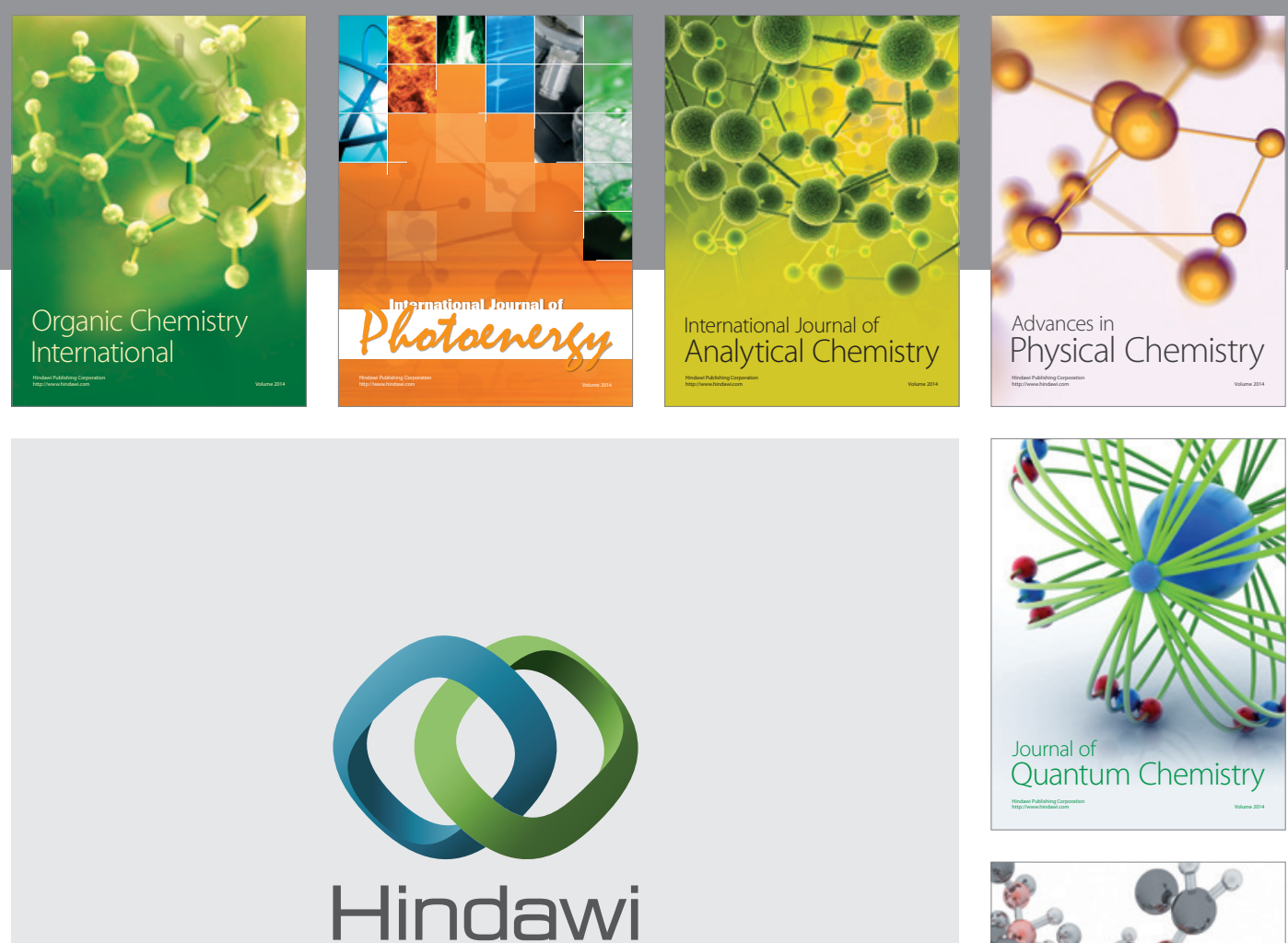

Submit your manuscripts at

http://www.hindawi.com

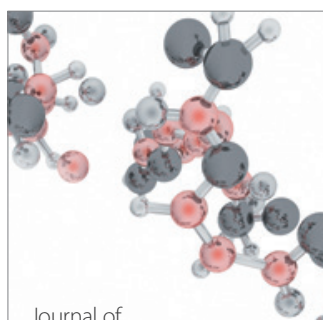

Analytical Methods

in Chemistry

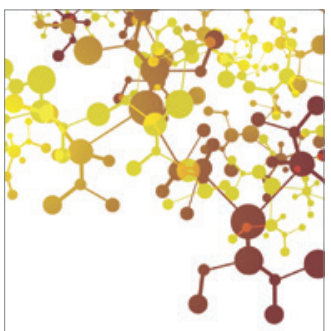

Journal of

Applied Chemistry

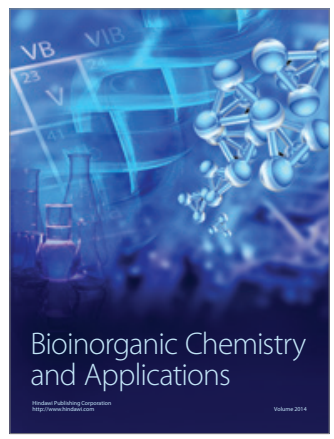

Inorganic Chemistry
